\title{
ELISEO PINEDO (1908-1969). UN CASO DE EDUCACIÓNY PROFESIÓN MUSICAL EN PROVINCIAS A MEDIADOS DEL SIGLO XX
}

\author{
Carlos Blanco Ruiz \\ Universidad de La Rioja \\ info@carlosblancoruiz.com
}

RESUMEN: En este estudio se puede ver cómo, a partir del ejemplo del músico riojano Eliseo Pinedo y de sus estrategias, se puede llegar a cambiar una tendencia histórica en una provincia, alcanzando una dignificación de la profesión a la vez que una socialización de la educación musical. Si bien tradicionalmente las enseñanzas musicales dependían de la condición económica de cada uno en origen, las acciones Ilevadas a cabo por Pinedo permitirán abrir el camino para que el acceso a la educación musical reglada sea universal. Lo lleva a cabo mediante la creación del Conservatorio Profesional de Música en Logroño, a la vez que consigue su reconocimiento en la sociedad mediante la cualificación del músico en las bandas de música.

Palabras clave: Educación musical, carrera musical, socialización, banda de música, Eliseo Pinedo, La Rioja, siglo XX.

\section{ELISEO PINEDO (1908-1969). THE MUSICAL EDUCATION AND PROFESSION ON THE PROVINCIAL LEVEL IN THE MIDDLE XX ${ }^{\text {TH }}$ CENTURY}

ABSTRACT: In this work, it is possible to discover the projects and strategies of Eliseo Pinedo, musician from La Rioja. Historical trends in any region can be changed, reaching dignity in musical profession and developing socialization in musical education as he did. Although musical teaching depended on the economic conditions, the actions managed by Pinedo allowed the access for the universal and official music education, by creating the Conservatorio Profesional de Música in Logroño. At the same time, he fought for the social acknowledgement in society as a musician through their qualification inside the wind bands. 
Keywords: Music education, musical career, socialization, wind band, Eliseo Pinedo, La Rioja, $X^{\text {th }}$ Century.

Recibido: 25 de marzo de 2020 Aceptado: 20 de noviembre de 2020

\section{Introducción}

En las primeras décadas del siglo XX, la profesión de músico en España adolece de una falta de reconocimiento social derivada de su función, relacionada más con el ocio que con la cultura. El hecho de que la formación inicial condicione también su orientación dentro del mismo ámbito de la profesión, deviene directamente del entorno social de cada músico en origen. Alcanzar otros repertorios y posiciones sociales era altamente improbable porque requería de un capital cultural que no estaba al alcance de todos por razón de su posición económica.

Por otro lado, la Guerra Civil española trajo tras de sí una serie de consecuencias extremas en todos los aspectos. En la política, una dictadura militar. En la sociedad, grandes desigualdades y una penuria que lastró la economía y afectó al resto de los aspectos colectivos. En el caso de la cultura, y en concreto en el de la música, por lo general considerada como una actividad económicamente residual, las dificultades para sobrevivir profesionalmente debieron de hacerse insoportables ${ }^{1}$. Para conocer cómo los músicos pelearon por vivir de su profesión se ofrece aquí una perspectiva desde el ámbito local, una historia desde abajo a través de una figura en parte olvidada y poco valorada durante años. Eliseo Pinedo (1908-1969), músico nacido en un entorno rural humilde, sirve como muestra de ese esfuerzo por hacerse un hueco profesional en la sociedad de su tiempo. También es un ejemplo de la lucha por la dignificación de la profesión y de la socialización ${ }^{2}$ de la educación musical de las generaciones

1. Si bien la mayor parte de los afiliados al régimen franquista encontraron pronto un puesto de trabajo o mantuvieron el que ya tenían antes de la Guerra, las distintas opciones de los músicos no vinculados al nuevo régimen pasaban por huir de España o realizar un exilio interior (F. Remacha o E. Fernández Blanco, por ejemplo), siempre tras una nunca justa depuración. El paro generalizado en la profesión obligó al nuevo régimen a adoptar medidas especiales, como la contratación obligatoria de músicos en los establecimientos hosteleros para contrarrestar el impacto laboral del uso de los equipos de reproducción mecánica. Martínez del Fresno, B., "Realidades y máscaras en la música de la posguerra." Dos décadas de cultura artística en el franquismo (1936-1956). Vol. II. Ignacio Luis Henares Cuéllar, José Castillo Ruiz, Gemma Pérez Zalduondo, María Isabel Cabrera García (coords.). Granada, Universidad de Granada, 2001, pp. 53 y 67.

2. Se trata de hacer posible el acceso a todos los bienes culturales y educativos sin privilegios de clase. Fernández Soria, J. M., Educación, socialización y legitimación política (España 1931-1970). Valencia, Tirant lo blanch, 1998, p. 39. 
venideras, facilitando sus estudios. Conocer su vida sirve para ser conscientes de las dificultades de la sociedad musical de posguerra en provincias y de los recursos y estrategias que se plantearon para su desarrollo profesional en un ambiente tan hostil.

Este espacio temporal y geográfico, con la música como eje sobre el que trabajar, tradicionalmente se ha considerado un objeto de estudio poco atrayente. A ello han contribuido las descripciones de partes interesadas como Federico Sopeña, Joaquín Turina, Joaquín Rodrigo o Antonio Fernández-Cid en las que se minusvaloraba el interés del período ${ }^{3}$. Sin embargo, a lo largo de las dos últimas décadas se han venido Ilevando a cabo una serie de congresos y publicaciones que han aportado nuevas perspectivas sobre la realidad social del mundo cultural. En ellos, la música se ha mostrado como un aspecto de importancia para comprender la sociedad en España en estas décadas, convirtiéndose casi en una tendencia ${ }^{4}$. La historiografía tradicional recoge aspectos vinculados a las situaciones más generales, desde puntos de vista legislativos, de funcionamiento de grandes instituciones o de figuras relevantes. Sin embargo, cada vez con mayor frecuencia, se van produciendo trabajos que pretenden reflejar la vida musical más allá de los cánones que afectan a personalidades y entidades de ámbito nacional. En este sentido, este artículo se imbrica en ese grupo de investigaciones que permiten la comparación de biografías y formas de actuar paralelas sobre sociedades fuera de los focos de las capitales principales del país. Se muestran así una serie de recursos comunes a los músicos de provincias que forman el tejido básico de la cultura, más allá de los hechos más conocidos que determinan el devenir histórico. En la misma línea, los estudios sobre el entorno de las agrupaciones bandísticas Ilevadas a cabo en la última década son un buen referente, puesto que muestran distintas perspectivas sobre entornos tradicionalmente menospreciados y que, sin embargo, conforman la base de la cultura musical del último siglo.

Con respecto al entorno de La Rioja, tanto el estudio de músicos como de la cultura en general en las décadas centrales del siglo XX está prácticamente sin realizar, si se exceptúan unas pocas publicaciones de ámbito etnomusicológico. La figura de Eliseo Pinedo está totalmente inexplorada y las escasas referencias que de él se hacen contienen errores que se han ido arrastrando en el tiempo, de uno a otro documento.

La metodología ha partido de un criterio positivista de recopilación, ordenación y estudio de fuentes para el apartado biográfico, puesto que ha sido necesario consultar documentos en diversos archivos públicos y privados que no habían sido examinados previamente. Posteriormente, se ha realizado una

3. Martínez del Fresno, B., "Realidades y máscaras...", pp. 31-82.

4. Pérez Zalduondo, G., "Música y poder en Sevilla (1936-1960)". Música en Sevilla en el Siglo XX. Miguel López Fernández (ed.). Granada, Libargo, 2018, pp. 203-228. 
ordenación y clasificación de los mismos en categorías biográficas, administrativas y artísticas que han permitido establecer el relato vivencial con suficientes instrumentos. Por otra parte, se ha hecho preciso acudir al método teórico para la comprensión de la historia y el entorno social de Pinedo, mediante la lectura de bibliografía referente al tema o de biografías de músicos con situaciones personales semejantes. También se han aplicado métodos deductivos para llegar a determinadas conclusiones, a partir del cotejo de circunstancias con puntos en común, que han permitido colegir dichas afirmaciones.

\section{Relato biográfico de Eliseo Pinedo}

El estudio se plantea desde tres ámbitos que discurren paralelos. Por un lado, la educación musical en las diversas clases sociales. Por otro, el oficio de músi$\mathrm{co}$, con sus distintas formas de desarrollo profesional. Un tercer aspecto estriba en el entorno musical profesional de la época, es decir, cómo se desenvolvían laboralmente. Todos ellos van apareciendo transversalmente al relato biográfico de Eliseo Pinedo.

\subsection{Primeros años en Zarratón (1908-1920)}

Pedro Eliseo Pinedo López nace en Zarratón, una pequeña población de setecientos habitantes junto a Haro, en La Rioja -entonces denominada Provincia de Logroño- y es su padre, Pedro Pinedo ${ }^{5}$, quien le enseña los rudimentos básicos de la música. En 1920, la familia ${ }^{6}$ se traslada a Haro donde esperan poder mejorar económica y socialmente.

En estos años, en una provincia como la de Logroño, el aprendizaje de la música se reducía esencialmente a dos tipologías de formación. Cuando la familia disponía de dinero, se accedía a la docencia privada, con músicos profesionales de la zona que preparaban de manera particular a los estudiantes, generalmente a domicilio. Entre las mujeres de clase media-alta era habitual recibir clases de piano como parte de su educación. Cuando alguien demostraba una capacidad especial, podía llegar a estudiar de una manera más especializada de cara a obtener una titulación en algún conservatorio del entorno, especialmente San Sebastián y Zaragoza ${ }^{7}$. Sin embargo, las mujeres no tenían

5. Pedro Pinedo era zapatero de profesión, pero también un gran aficionado a la música y un dinamizador local que introdujo a sus hijos en el ambiente musical. Fuente: diversos padrones del Ayuntamiento de Zarratón. Años 1900-1916.

6. Pedro Pinedo Balzola y Elisa López Cereceda son sus padres. Sus hermanos fueron Félix Clemente (Clemente, 1903-1982), Amada (1905-1987) y Benedicto (Bene, n. 1911). Fuente: padrones del Ayuntamiento de Haro. Años 1920-1947.

7. Blanco Ruiz, C., Las claves de la música de M. $^{a}$ Dolores Malumbres. Logroño, Instituto de Estudios Riojanos, 2009, p. 30. 
un acceso fácil a la vida profesional como músico pese a su titulación, especialmente en provincias ${ }^{8}$.

La otra posibilidad formativa consistía en aprender el oficio de manera complementaria a una profesión principal, como una afición, o con el fin de completar el sueldo necesario para sustentar a la familia. Este aprendizaje se realizaba con músicos locales, en los seminarios diocesanos, en las academias de las bandas o en las instituciones de beneficencia. Todas estas entidades servían como base sobre la que el músico se integraba a la sociedad musical del entorno, de una manera eminentemente práctica y casi nunca resultaba en un reconocimiento oficial. Pocos de los músicos que adquirían esta educación musical no reglada se focalizaban exclusivamente en la música y sus trabajos principales solían ser otras profesiones, a las cuales complementaban pecuniariamente con su participación en bandas, orquestinas u otras agrupaciones ${ }^{9}$.

\subsection{Formación musical en Haro (1920-1935)}

Tras adquirir la base musical con su padre, realiza estudios en la Academia de la Banda Municipal de Haro. En esta agrupación toca la trompeta desde el año 1922 al año $1933^{10}$ cuando, junto con su hermano Bene -flauta en la banda-, deciden abandonarla por motivos ideológicos ${ }^{11}$. Son años de constante práctica musical, a la vez que de educación teórica. Dado que Eliseo destacaba entre los demás aficionados, pronto adquiere relevancia solista dentro de la formación y comienza a estudiar más profundamente. Para ello acude al músico local Virgilio Mendiola y a Basilio Miranda, organista de la iglesia parroquial de Santo Tomás Apóstol de Haro. Con él aprende armonía y recibe una clara orientación profesional que le hace considerar sus posibilidades como músico ${ }^{12}$.

La profesión de músico no era una opción como para vivir cómodamente en las primeras décadas del siglo XX, salvo que se dispusiera de unos estudios reglados y se reorientara el trabajo y con ello el repertorio. Quien estudiaba con miras a la obtención de un título en un conservatorio, por lo general trabajaba repertorios de la denominada música clásica tradicional. Además del estudio del instrumento conforme a un plan reglado, se trabajaba el resto de asignaturas

8. Castañón Rodríguez, M. R., La educación musical en España durante el franquismo (1939-1975). Valladolid, s.e., 2009, p. 38.

9. Ayala Herrera, I. M., Música y municipio: marco normativo y administración de las bandas civiles en España (1931-1986). Estudio en la provincia de Jaén. Granada, s.e., 2013, p. 72.

10. Fuente Rosales, F., Laureada Banda Municipal de Música de Haro. Logroño, Instituto de Estudios Riojanos, 2005, p. 227.

11. Debido a que el ayuntamiento republicano obligó a desfilar a la banda en el Viernes Santo de ese año de 1933, a lo que los hermanos, de fuerte convicción religiosa, se negaron. Fuente Rosales, F., Laureada Banda..., pp. 27-29.

12. Fuente Rosales, F., Laureada Banda..., pp. 183-184. 
que conformaban el currículo como Armonía, Historia de la música, Estética o Folclore, por ejemplo. Lo que estaba claro es que si la orientación se realizaba de forma académica, el repertorio era eminentemente clásico y las posibilidades laborales estaban dirigidas hacia la profesionalización como concertista, músico de orquesta o docente titulado. Sin embargo, cuando se había aprendido en el seno de una academia de una banda o en un seminario, al estudiar con los aficionados locales o en las instituciones de beneficencia, la orientación era otra. Se solía participar en las formaciones de la zona, por supuesto en la banda si uno es educando de la misma o mostraba cierta destreza con los instrumentos de viento, o en pequeñas formaciones orquestales. A lo largo del siglo XIX y de las primeras décadas del siglo XX se hicieron comunes también los sextetos formados por piano, dos violines, viola, violonchelo y contrabajo -es decir, una pequeña orquesta de cuerda formada por solistas a la que se añade el piano- y que solían interpretar un repertorio mixto entre la música culta y la popular ${ }^{13}$. Incluso a estas, ocasionalmente, en función de las disponibilidades de los músicos o de las necesidades del repertorio ${ }^{14}$, se les unían otros instrumentos de la orquesta: bien una trompeta, una flauta o una trompa. Una opción laboral más eran las orquestinas o formaciones mixtas de música popular que, a partir de 1910, fueron uno de los recursos más importantes para los músicos durante más de cuatro décadas. Estas orquestinas actuaban en los cafés, en los casinos o en salas de baile porque su repertorio estaba esencialmente orientado al entretenimiento y al consumo pasivo de la música ${ }^{15}$. Sus interpretaciones contienen una mezcla de canciones de estilos populares -que van cambiando con el paso del tiempo y los gustos del público- y ritmos que cada vez se hacen más mestizos. Del vals y la polca del siglo XIX se dio paso a los danzones cubanos, los boleros y, a partir de la década de 1920, a todos los derivados de la música afroamericana bajo un amplio paraguas denominado jazz ${ }^{16}$. Por lo general, la mayor parte de esos músicos no disponían de formación reglada y su oficio era principalmente otro, siendo el trabajo en la banda, la orquesta o la orquestina un plus necesario para poder alcanzar un salario suficiente con el que mantener a la familia sin penurias.

13. Mansergas Carceller, Y., El Sexteto en la Música Española de Salón: de la Restauración a la Guerra Civil. Valencia, s.e., 2008, pp. 45-48 y 175.

14. Aunque habitualmente trabajaban con adaptaciones específicas para cada formación, siendo la música original una excepción en el repertorio.

15. Sin embargo, es habitual encontrar incursiones en el repertorio clásico, que era pasado por el filtro del estilo comercial de estas orquestinas y que no eran del agrado de sectores de la crítica más conservadora, especialmente en la primera época del franquismo, cuando el Sindicato prohíbe la interpretación de obras clásicas adaptadas al estilo de jazz. Martínez del Fresno, B., "Realidades y máscaras...", p. 68.

16. Iglesias, I., "(Re)construyendo la identidad musical española: el jazz y el discurso cultural del franquismo durante la Segunda Guerra Mundial" Historia Actual Online 23 (2010), pp. 119-135. 


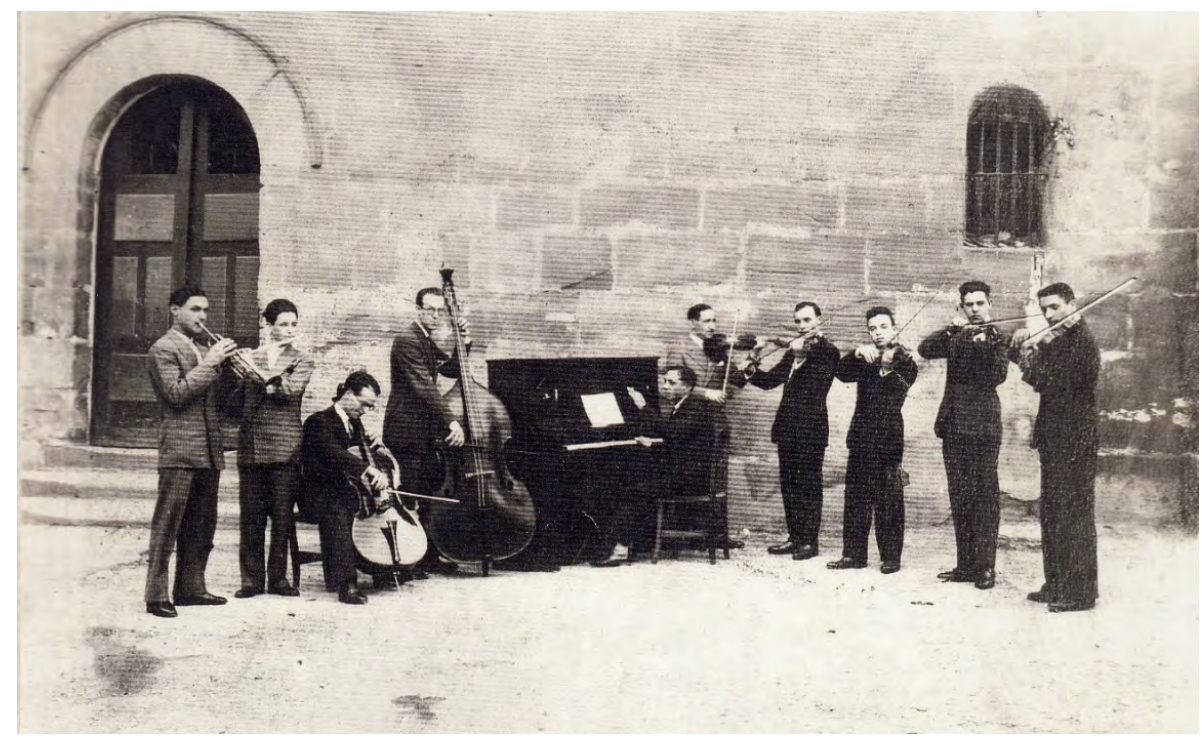

Imagen 1. Orquestina del Teatro Bretón de Haro. A la izquierda, tocando la trompeta, Eliseo Pinedo. Fuente: Archivo de M. ${ }^{a}$ Teresa Hernández (AMTH).

Haro vivió, en los años veinte y treinta, una eclosión de actividades culturales, con gran participación local, y con numerosas asociaciones culturales que promocionaban y combinaban teatro, música y espectáculos. También disfrutaron de formaciones y propuestas de rango nacional que se acercaron a la ciudad jarrera a mostrar sus repertorios en las giras por todo el territorio español. Bandas municipales de gran parte de la geografía española, la Orquesta Filarmónica de Madrid dirigidos por Bartolomé Pérez Casas (1922), la Orquesta Sinfónica de Madrid con Enrique Fernández Arbós (1936) o la Orquesta Sinfónica Municipal de Bilbao (1939) bajo la batuta de Jesús Arámbarri son una muestra de ello ${ }^{17}$.

Pinedo, en este ambiente cultural tan activo, con sus básicos conocimientos musicales y toda su experiencia en varias de las formaciones locales, comienza a escribir música. Y lo hace para los posibles instrumentales de que dispone en la ciudad de Haro. En el año $1933^{18}$, la banda y las orquestinas son las agru-

17. Fuente Rosales, F., Laureada banda..., pp. 178, 246 y 254.

18. Pese a que en este año 1933 abandona la Banda de Haro, mantendrá una buena relación con la institución y con los músicos, incluidos los directores de las mismas durante toda su vida, colaborando con ellos, incluso dirigiéndoles puntualmente por invitación. De hecho, su hermano Clemente siguió en la formación hasta su fallecimiento en el año 1982. Fuente Rosales, F., Laureada banda..., p. 429. 
paciones que rigen la vida musical, así que para ellos compone sus primeras obras. De ese año se pueden documentar ${ }^{19}$ cinco obras: Tango amigo (tango), Malacate (danzón), Glorian (fox-trot), Añoranzas (tango) y Rioja Santiago (pasodoble). Como se observa, es música orientada al consumo inmediato en los bailes. Este es uno de los principales recursos para ganarse la vida como músico o como segundo ingreso en toda España, y por extensión en la ciudad jarrera, no solo en la década de los 1930, sino también en la posguerra, tal y como se refleja en los datos de la SGAE. Esta sociedad indica que, en el año 1942, la recaudación por Pequeño Derecho ${ }^{20}$ en la provincia de Logroño supone dos tercios de la recaudación total ${ }^{21}$. A estas obras de Pinedo les siguieron otras en forma de pasodobles, valses y géneros vinculados al denominado jazz, es decir, músicas de moda para ambientes de ocio. Su gran capacidad para la composición y su interés por la creación hacen que Basilio Miranda, una vez más, le oriente profesionalmente para la música.

\subsection{Los estudios en Madrid (1935-1947)}

En sus datos personales para el servicio militar -realizado en Bilbao en 1929- indica que sus oficios son zapatero y músico ${ }^{22}$. En el padrón municipal de Haro de 1935 aparece como zapatero, pero en el de 1940 se indica por primera vez su profesión como músico ${ }^{23}$. El proceso de autoafirmación como tal proviene de un doble hecho. Por un lado, a partir de 1936 crea el "Repertorio Ediciones Musicales E. Pinedo", una editorial con la que autopublica sus obras para orquestina. Evidentemente él conocía, como intérprete, el pago a realizar a la Sociedad de Autores de los derechos de ejecución de las músicas de bailables en cada sesión. Si el autor y el editor eran él, los beneficios podrían llegar a ser importantes. Como se ha visto, gran parte de los músicos del momento sobrevivían exclusivamente de estos repertorios. Así se embarca en un proyecto que

19. tas obras, junto con otras dos de 1935, fueron catalogadas en el año 2003 en el Archivo Provincial de La Rioja, cuando el Registro de la Propiedad Intelectual (RPI) estaba integrado en el fondo de la Consejería de Cultura. Actualmente, algunas se encuentran perdidas y otras localizadas en el archivo general del RPI en Madrid.

20. Concepto heredado del siglo XIX cuando la entonces SAE (Sociedad de Autores Españoles) trata de organizar y defender los derechos de autor de sus socios. Frente al "Gran derecho" de las obras dramáticas y lírico-dramáticas se gestionaban otras liquidaciones por la ejecución del resto de las obras musicales dentro del apartado "Pequeño derecho". Guadamuro García, I., "La explotación del teatro lírico en dominio público: el caso de la opereta vienesa en España en las primeras décadas del siglo XX". Musicología en el siglo XXI: nuevos retos, nuevos enfoques, de A. Presas y B. Lolo (coords.). Madrid, Sociedad Española de Musicología, 2018, p. 575.

21. Martínez del Fresno, B., "Realidades y máscaras...", p. 55.

22. Hoja de Filiación de Eliseo Pinedo en el Archivo General Militar de Guadalajara.

23. Padrones de los años 1935 (pág. 142-143), 1940 (pág. 184), 1945 (pág. 200). Fuente: Archivo del Ayuntamiento de Haro. 
Ilega hasta el año 1950, si bien de manera más intensa en los primeros años. Esta será la fuente principal de ingresos que le va a permitir su segundo proyecto en la época, que consiste en la obtención del título de composición en el Real Conservatorio de Música y Declamación de Madrid ${ }^{24}$. Se trata de una inversión de los beneficios obtenidos por la participación en orquestinas y la autoedición de partituras que le permitirá, desde 1935, comenzar los estudios de manera privada con Emilio Vega Manzano ${ }^{25}$.

Vega, una de las personalidades más reconocidas en el ámbito musical docente madrileño de las décadas de los años veinte, treinta y cuarenta, se convierte en una referencia para Pinedo en diferentes sentidos. En las cartas que se intercambiaban puede apreciarse en la figura del maestro un perfil humano ${ }^{26} y$ de consejero hacia el alumno. La fama de Vega provenía de la cercanía en la docencia y de su experiencia como compositor y director, además del respeto del que disfrutaba en los círculos profesionales, donde tenía grandes contactos. La mayor parte de la correspondencia entre Pinedo y Vega trata sobre composición y contrapunto. La forma de enseñanza a distancia se practicaba con relativa normalidad, incluso con maestros del extranjero ${ }^{27}$. En un determinado momento, se visitaba físicamente al maestro, pero los ejercicios se enviaban regularmente por correo y se devolvían corregidos, con observaciones y nuevas tareas. El pago se realizaba mediante giro postal. El título de composición lo obtuvo en septiembre de $1943^{28}$, cuando finaliza quinto curso de composición y folclore en unas maratonianas sesiones de exámenes libres ${ }^{29}$.

Paralelamente, Emilio Vega le preparó también para acceder al Cuerpo Nacional de Directores de Bandas de Música Civiles, habilitación que consigue en el concurso de ingreso al Cuerpo de 1940. La convocatoria se realizó en ese año ${ }^{30}$, aunque las pruebas se llevaron a cabo en enero de 1941. La práctica para aprender esta especialidad debió ser presencial, aprovechando los periodos de estancia en la capital para los estudios o exámenes del conservatorio. Las razo-

24. Entrevista a M. ${ }^{a}$ Teresa Hernández el 31 de julio de 2018.

25. Por la correspondencia entre Pinedo y Vega, se deduce que Miranda era amigo de este último y que posiblemente fue el impulsor de la idea de conseguir una formación suficiente para obtener la titulación oficial de composición. Fuente: AMTH.

26. Pese al tratamiento de usted entre ambos a lo largo de su relación docente, algo habitual en la época.

27. Seguí, S., Manuel Palau (1893-1967). Valencia, Consell Valenciá de Cultura, 1999, p. 103.

28. Había aprobado las pruebas de acceso al mismo en septiembre de 1940.

29. Entre el 9 de junio y el 8 de octubre de 1941 realiza desde $1^{\circ}$ de solfeo hasta $4^{\circ}$ de composición. El 2 de octubre de 1943 finaliza $5^{\circ}$ de composición y por lo tanto la carrera según el plan vigente. Fuente: boletines de notas del AMTH.

30. Orden de 9 de julio de 1940 por la que se convocan oposiciones para ingreso en el Cuerpo de Directores de Bandas de Música. BOE núm. 194, de 12 de julio de 1940, del Ministerio de la Gobernación, p. 4.824. 
nes para que Pinedo se lanzara a la obtención de título pueden encontrarse en este texto de Julio Gómez, alumno como Vega de las clases de Emilio Serrano en el conservatorio madrileño ${ }^{31}$.

Nada ha habido para mí tan descorazonador como ver que había que hacer compositores de quienes no eran músicos. Y en lo que fuera he puesto siempre mi mayor esfuerzo. Por esto les he impulsado siempre hacia la práctica profesional de la música. Les he aconsejado ingresar en el Cuerpo de Directores de Bandas Civiles no como un fin, sino como un medio, el más eficaz, de que abandonasen cuanto antes la música muerta de la Pedagogía para enfrentarse, siquiera fuera modestamente, con la música viva de la realidad ${ }^{32}$.

Pero incluso antes de terminar los estudios oficiales y de forma paralela a estos, su actividad en Haro se multiplica, trabajando en distintas composiciones y ediciones de música. Son años muy dinámicos y creativos donde trabaja intensamente, lo que le produce incluso problemas de salud ${ }^{33}$. De esta época data su primer trabajo para el teatro lírico, una zarzuela grande ${ }^{34}$ denominada EI Montañés ${ }^{35}$ (1942) a la que seguirían en los siguientes años La masía del cuervo (1942), La Titiritaina (1944), Ernestina (1944), Paloma la desdeñosa (1946) y S. E. El Sainete (s.f.). La razón de la orientación y la composición de estas zarzuelas -entendidas estas como la representación teatral en la que se alternan los textos recitados y cantados, pero con una gran variedad de estilos- se puede encuadrar en la promoción que del género se realizó en la inmediata posguerra en España. Las directrices del nuevo régimen, a partir de la creación de la Junta Nacional de Teatro y Conciertos y la Comisaría General de Teatros Nacionales y Municipales (noviembre de 1938) contenían, entre otras medidas, la promoción de la música netamente española ${ }^{36}$-por lo general con fines instrumentales de propaganda política. En esta línea se encuentra el fomento de la zarzuela y el sainete que, tras el fracaso de la "creación" de la ópera española, se convirtieron en un bastión de

31. Iglesias, A., Escritos de Julio Gómez. Recopilación y comentarios. Madrid, Alpuerto, 1986, p. 226.

32. Iglesias, A., Escritos..., pp. 282 y 283.

33. Carta de Emilio Vega Manzano a Eliseo Pinedo de 12 de marzo de 1943. Fuente: AMTH.

34. Sobre los conceptos de zarzuela grande, género chico, opereta, etc. se recomienda acudir a libros como el de José Luis Temes sobre el género. Temes, J. L., El siglo de la Zarzuela. 1850-1950. Madrid, Ediciones Siruela, 2014.

35. Que en el año 1947 obtendría el tercer accésit en el Concurso Nacional de Zarzuelas de Radio Nacional de España.

36. Medina, Á., "Música española 1936-1956: rupturas, continuidades y premoniciones." Dos décadas de cultura artística en el franquismo (1936-1956). Vol. I. Ignacio Luis Henares Cuéllar, José Castillo Ruiz, Gemma Pérez Zalduondo, María Isabel Cabrera García (coords.). Granada, Universidad de Granada, 2001, p. 62. 
la cultura popular del régimen autárquico de la década ${ }^{37}$. Sin embargo, la promoción se centró en unos pocos compositores, intérpretes y empresarios y los públicos acudían cada vez más al cine sonoro, al fútbol, a los toros o a los espectáculos como la revista, todos ellos ejemplos de ocio pasivo ${ }^{38}$ y de consumo inmediato. El género no consiguió revitalizarse por parte de aquellos a los que generacionalmente les correspondía. No es que no lo intentaran, pero el problema fue que no cuajó en el público. Paulatinamente se sustituyó por la revista o por la zarzuela arrevistada ${ }^{39}$ y las figuras famosas se llevaban la mayor parte de la taquilla en las grandes ciudades. En provincias se imitaba todo. Incluso en La Rioja existía un gran representante de esta nueva línea a nivel nacional: Pepe Blanco ${ }^{40}$.

Finalmente, Pinedo obtiene el título de composición en el Real Conservatorio Superior de Música de Madrid ${ }^{41}$ (1943) y, junto con el de director de banda ${ }^{42}$ (1941) se dispone a ganarse la vida en el entorno de Haro. La actividad musical que desarrolla es extensa: continúa haciendo publicaciones en su editorial, trabaja como trompetista en las formaciones locales, compone mucho, como se ha podido ver por el volumen de obras para el teatro lírico a las cuales se añaden las obras de pequeño formato para los bailes, adquiere cargos de responsabilidad en la Agrupación Artística Harense ${ }^{43}$ (desde 1934) y en la Agrupación Recreativa Pro-Arte ARPA ${ }^{44}$ (1945). Incluso procedió a extraer algunos números de sus zarzuelas para ser llevadas a orquestinas y los editó en sus Ediciones Musicales Eliseo Pinedo. Hasta que en 1947 consigue su primer gran logro profesional al obtener la plaza de Director de la Banda de Tudela.

\subsection{Dirección de la Banda Municipal de Tudela (1947-1953)}

La Diputación de Navarra, por su aforamiento, no estaba incluida dentro de las zonas de ámbito de la Asociación Nacional de Directores de Bandas

37. Pérez Zalduondo, G., Una música para el 'Nuevo Estado'. Música, ideología y política en el primer franquismo. Granada, Libargo, 2013, p. 126.

38. González Manrique, M. J., "Sociedad, ocio y comunicación de masas en el franquismo (1939-1956)". Dos décadas de cultura artística en el franquismo (1936-1956). Vol. I. Ignacio Luis Henares Cuéllar, José Castillo Ruiz, Gemma Pérez Zalduondo, María Isabel Cabrera García (coords.). Granada, Universidad de Granada, 2001, p. 154.

39. Temes, J. L., El siglo de la Zarzuela..., p. 104.

40. José Blanco Ruiz (Logroño, 19 de marzo de 1911 - Madrid, 17 de diciembre de 1981) se inició artísticamente después de la Guerra Civil imitando a otros cantantes. En 1944 grabó su primer disco, creó una compañía y llegó a registrar más de 150 canciones con una gran repercusión a nivel nacional.

41. Fuente: expediente académico en el archivo del Real Conservatorio Superior de Música de Madrid.

42. Ayala Herrera, I. M., "Música y municipio...", pp. 240, 241 y 299.

43. Fuente Rosales, F., Laureada Banda..., p. 243.

44. Fuente Rosales, F., Laureada Banda..., p. 272. 
de Música sino en la Asociación de Directores de Bandas Municipales de la Región Vasco-Navarra, quienes fueron pioneros en la consecución de los derechos de los directores de bandas ${ }^{45}$. La Diputación hace pública en 1947 la convocatoria de una plaza de director de la Banda Municipal de Música de Tudela (Navarra) ${ }^{46}$. Se crea un tribunal ${ }^{47}$ y el 1 de mayo de 1947 se realiza el nombramiento de la plaza por oposición de Director a favor de Eliseo Pinedo, tomando posesión el 13 de mayo. A partir de este momento, Tudela se convierte en un laboratorio de pruebas para sus proyectos, enfocados a la dignificación de los músicos y a la socialización de la enseñanza musical, Ilegando a todos los estratos económicos.

En el primer aspecto, Pinedo comienza la reorganización de la banda que había quedado maltrecha por la inacción de su anterior director, Luis Gil Lasheras. Pocos meses después de su llegada al cargo ya se le reconoce la labor por parte de los músicos y, oficialmente, por las autoridades loca$\mathrm{les}^{48}$. Esta labor, además de las numerosas actuaciones de la banda, implica también la organización de la actividad y la dirección de la Agrupación Filarmónica Gaztambide del Orfeón de Tudela, con numerosas actuaciones en el teatro de la ciudad. Esta actividad comprende tanto a la propia orquesta y coro como a otras formaciones y grupos invitados. Continuando con el plan de consolidación y estabilidad de la banda, consigue convocar en propiedad numerosas plazas para equilibrarla y dotarla de una mayor calidad y se establece un nuevo reglamento en la línea del proyecto cualitativo con el que se identificaba ${ }^{49}$.

En el segundo aspecto, desde el Boletín de la Asociación de Directores se incide en que las bandas "constituyen la Escuela elemental artística [...] pero el conocimiento de las materias del arte, solo lo proporciona la didáctica, y en este aspecto, las Bandas, con todos sus defectos, susceptibles de corrección, es lo único que existe, aparte de los Conservatorios" ${ }^{\prime 50}$. Una idea que se aplica en favor de la creación de academias con unas miras más ambiciosas que las habituales del entorno bandístico. Posiblemente esta doctrina se la transmitiera

45. Ayala Herrera, I. M., "Música y municipio...", p. 128.

46. El 20 de febrero de 1947 se aprobaron las normas para la provisión mediante oposición de la plaza de Director de la Banda de Tudela. Ayuntamiento de Tudela, "Pleno del M. I. Ayuntamiento de Tudela" Actas de la Sesión del Pleno 1947, fol. 185.

47. Presidido por el alcalde de Tudela y formado por Estanislao Lirón de Robles, Jesús Castellano, Fernando Remacha y Juan Berruezo. Ayuntamiento de Tudela, "Pleno...", fol. 185.

48. Ayuntamiento de Tudela, "Pleno...", fol. 20v, 35 y 126.

49. Contiene en esta reforma la consideración de los educandos con su derecho a remuneración mensual por su asistencia a los ensayos, redundando en el interés por la dignificación del músico desde las bases. Ayuntamiento de Tudela, "Pleno...", fol. 128v y 129.

50. Asociación Nacional de Directores de Bandas de Música Civiles, “iiGuerra a las Bandas!!" Boletín de la Asociación Nacional de Directores de Bandas de Música Civiles (diciembre de 1935), pp. 13 y 14. 
a Pinedo su maestro Emilio Vega, presidente de la asociación durante diez años, aunque se pueden encontrar ejemplos en el propio Haro, con Miguel de la Fuente $^{51}$ o en Córdoba, donde se plantean "costear a los jóvenes menesterosos la instrucción musical necesaria con vistas a una futura profesionalización" ${ }^{\prime 52}$. Pinedo, cuyo puesto como Director de la Banda Municipal de Tudela Ileva vinculada la dirección de la Academia de la propia entidad municipal, solicita en diciembre de 1948 "la ampliación de la misma con la enseñanza de instrumentos de orquesta, rondalla y voces, formando una verdadera academia municipal de música" ${ }^{53}$. El ayuntamiento acepta ${ }^{54}$ y se pone en marcha un nuevo concepto de Academia.

Se puede concluir que Pinedo entiende la enseñanza de la música de una manera accesible no solamente a los educandos de la banda, los acogidos por las beneficencias o a las familias pudientes que pudieran pagarse unas clases privadas. Trata de poner la música al alcance de la población interesada en convertirla en una profesión mediante la socialización de la enseñanza musical. Pinedo es quien aporta el capital social extra que permite una trayectoria ascendente en la escala social ${ }^{55}$. Algo que él tuvo que conseguir a base de retrasar su formación hasta lograr el capital económico que le permitiera realizar el cambio de escala y que quiso facilitar a las futuras generaciones.

Este sería un proyecto que se trunca parcialmente, por su parte, cuando en 1953 obtiene la plaza de Director de la Banda Provincial de Logroño, abandonando definitivamente la localidad navarra.

\subsection{Dirección de la Banda Provincial de Logroño (1953-1969)}

Pinedo se traslada a Logroño ${ }^{56}$, y con él se van sus estrategias, puestas en marcha en Tudela con buenos resultados, al parecer. Por ello, la plaza de Logroño supone para él una continuidad del proyecto personal.

La Banda Provincial de Logroño estaba dirigida hasta el momento por Fermín Irigaray, a partir de las bases personales provenientes de la beneficencia riojana, con una función más social que profesional. Por su parte, la Banda

51. Fuente Rosales, F., Laureada Banda..., pp. 229 y 230.

52. Toro Egea, O. M., La enseñanza de la música en España (1823-1932): documentación de materiales. Córdoba, Universidad de Córdoba, 2010, p. 36.

53. Ayuntamiento de Tudela, "Pleno...", fol. 192.

54. Aunque Pinedo solicitaba por este concepto un aumento de 1.000 pesetas, el Pleno Municipal eleva la subvención para la enseñanza de las clases propuestas a 3.000 pesetas.

55. Bourdieu, P., La distinción. Criterio y bases sociales del gusto. Barcelona, Taurus, 2017 [1979], pp. 125, 128.

56. El nombramiento se produjo el 5 de febrero de 1953 y tomó posesión del cargo el 23 de abril. Actas de la Diputación Provincial de Logroño, 1953, fol. 147v-148. 
de la ciudad de Logroño ${ }^{57}$ también había estrenado dirección -aunque con una mayor remuneración- en las mismas oposiciones, con José Cabañero García. Sin embargo, la perspectiva de Cabañero no encajó con las posibilidades de la formación musical. Apoyándose en su exclusiva capacidad musical pretendió alcanzar un elevado nivel sin valorar de lo que disponía realmente y, sobre todo, sin apreciar su base humana, despreciando a la persona y adoleciendo de ser el "técnico absoluto, seco y sin la flexibilidad que el ejercicio del cargo requiere" que ya anunciaba el Boletín de 1935 de la Asociación Nacional de Directores como tipología a evitar ${ }^{58}$. Finalmente, consiguió disolver la banda a los seis meses de su incorporación al cargo, eso sí, cobrando un sueldo del $80 \%$ hasta su jubilación en enero $1976^{59}$. Los antiguos componentes -algunos históricamente reticentes a la fusión con la "banda de la Bene" - remiten en abril de 1954 una instancia a la Diputación en la cual se ofrecen "a formar parte de la Banda provincial de acuerdo con las condiciones que por ambas partes se estipulen"60. La Banda Provincial que recibe Pinedo en 1953 es un grupo de veintidós músicos. En 1954 se solicitan uniformes para cuarenta músicos, ampliándose a cincuenta en $1956^{61}$. Pero, además del incremento cuantitativo, Pinedo realiza un crecimiento cualitativo, apoyándose en la confianza y el factor humano, desarrollando ese concepto pedagógico tan actual de promoción de la inteligencia emocional, y dirige una banda que se convierte en la agrupación representativa de la sociedad riojana.

Realiza anualmente numerosas actividades en colaboración con el Ayuntamiento, Ilegando a los ciento doce actos programados por este en 1960. Estas actuaciones comprenden conciertos -miércoles, sábado y domingos de junio a agosto con hora y media duración-, procesiones, vísperas, traslados de santos o vírgenes, bailables a medio día, por la tarde o por la noche, dianas, vaquillas, corridas de toros o pasacalles. A estas, hay que añadir otras actividades tanto de la Diputación -al fin y al cabo sus responsables oficiales

57. Aunque aparece nombrada como "Municipal", realmente era una banda subvencionada por el municipio, sin empleados dependientes de este. Fuente: expediente administrativo de José Cabañero García. Archivo del Ayuntamiento de Logroño.

58. Asociación Nacional de Directores de Bandas de Música Civiles, "A opinar se ha dicho." Boletín de la Asociación Nacional de Directores de Bandas de Música Civiles Año I, n. ${ }^{\text {. }}$ 9 (octubre de 1935), p. 6.

59. Resolución de la declaración de excedencia forzosa del cargo de Director de la Banda de Música. Fuente: Archivo Ayuntamiento de Logroño.

60. Escrito de 7 de mayo de 1954, de la Secretaría de la Diputación Provincial de Logroño, en la que solicitan informe a Eliseo Pinedo sobre la posibilidad de la admisión. Archivo del Conservatorio Profesional de Música de La Rioja (ACPMLR).

61. Por las liquidaciones de los repartos mensuales se sabe que en 1955 estaba compuesta por cuarenta y siete músicos, en 1957 por cuarenta y cuatro, en 1958 por cuarenta y en 1959 por treinta y ocho, divididos en varias categorías, y a los que habría que añadir los educandos, a razón de entre cuatro a ocho por año. Hojas de reparto de la banda de los años 1955-1959. ACPMLR. 
directos- como del Gobierno Civil y del Gobierno Militar de Logroño, algunas pintorescas en exceso ${ }^{62}$.

En este sentido, Pinedo trabajó por la dignificación de los músicos en la sociedad e intentó en todo momento que los músicos de su Banda estuvieran socialmente bien considerados. Por ello, solicita regularmente un vestuario digno, e incluso indica a los responsables que:

Debería evitarse que la Banda actúe en tablados, que da la sensación de una "charanga" amenizando las fiestas de un pueblo. Debe darse a la Banda todo lo que ella va consiguiendo con su trabajo, procurando dignificarla a medida que se supere su cometido artístico para que los componentes de la misma, viendo las consideraciones de que son objeto, se crean en el deber de corresponder ${ }^{63}$.

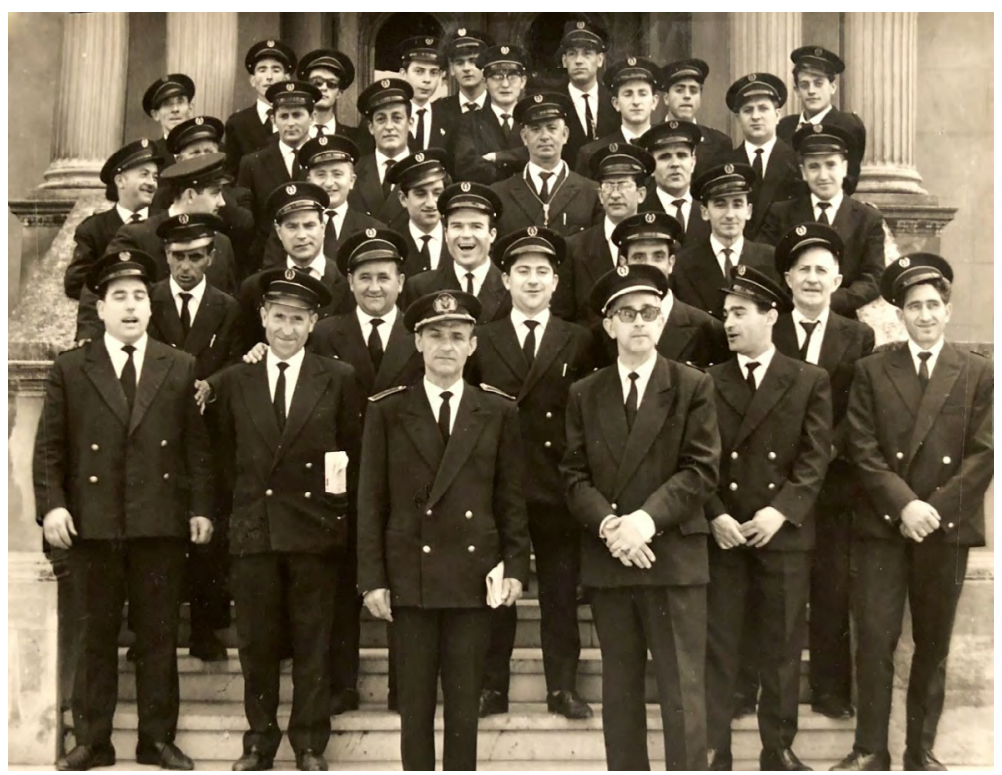

Imagen 2. Banda Provincial de Música de Logroño, en las escalinatas del Palacete de Presidencia. En la fila inferior, Eliseo Pinedo (izquierda) y José Luis Alonso (derecha, con gafas). Fuente: AMTH.

62. Los documentos que sirven de fuente para todas estas afirmaciones pertenecen al ACPMLR. Lamentablemente, este contiene una enorme cantidad de documentación que está clasificada en cajas y archivadores sin ningún tipo de catalogación bibliográfica o archivística que permita su localización de manera rápida y ordenada.

63. Borrador de carta dirigida al Presidente de la Comisión de Festejos del Ayuntamiento de Logroño solicitando la contratación para las actividades musicales del siguiente año. S.f. ACPMLR. 
En paralelo se modifica el funcionamiento de la academia vinculada a la banda. Pinedo accede a una Academia que refleja una carencia total de infraestructuras "ya que actualmente funciona deficientemente en el Asilo ${ }^{64}$ Provincial" 65 . Solicita al entonces Presidente de la Diputación, el arquitecto Agapito del Valle, que le facilite un sitio digno donde impartir las clases de los educandos de la Banda. Surge así la idea de la Academia Provincial de Música de Logroño (1954) con la orden del presidente de "Eliseo, tienes razón, anda que te arreglen las carboneras ${ }^{66}$ y empieza a trabajar" ${ }^{\prime \prime 7}$.

Tras una prueba de funcionamiento, que se lleva a cabo entre marzo y junio, se comprueba que es un éxito y la Diputación se plantea entonces su continuidad a lo largo del curso escolar de 1954-1955. Se crea en septiembre de 1954 el Patronato de la Academia de Música ${ }^{68}$ y se elige por un concurso público un equipo docente provisional ${ }^{69}$. Fueron seleccionados cuatro profesores titulares: Amelia Romero del Saz, Estrella Sacristán Torralba, Lorenzo Blasco Martínez y Pilar Tudela Angulo y tres profesores auxiliares: Pedro Sáenz Sada, Pascual Ayala Domínguez y Manuel López Astorga, que constituirán la Junta de Cultura de la Academia, con funciones de control y fiscalización tanto de la Academia como de la Banda Provincial ${ }^{70}$.

64. El edificio de la Beneficencia Provincial, donde también ensayaba la banda, fue inaugurado bajo el gobierno de Sagasta en 1887. Su función era ser un "centro integral de ocupación y reinserción a través del trabajo y la enseñanza de los niños y jóvenes, por lo que tuvo talleres de alpargatería, panadería, carpintería, hojalatería". Gómez Urdáñez, J. L., "De la Caridad a la Filantropía. Antecedentes históricos del Tercer Sector y la Economía Social en La Rioja". Polska.Hiszpania, wczoraj i dzis, Biblioteka Polsko-Iberyjska (Biblioteca Polsko Iberijska) 5 (2012), p. 194. Sin embargo, se convirtió en un edificio multiusos y, tras guerra y la posguerra, llegó a ser en un edificio semiabandonado.

65. Actas de la Diputación Provincial de Logroño, 1953, sig. 16/2.

66. Este espacio estuvo inicialmente en las denominadas "carboneras". Eran los sótanos del Palacio de Gobierno, que es la actual sede de la Presidencia de La Rioja, ubicado en Vara de Rey, 3. Originalmente tenían el uso de almacenes, también de acopio de carbón, y Agapito del Valle mandó limpiarlos y adecentarlos mínimamente para poder impartir la docencia de música. Fuente: entrevista a $M^{a}$ Teresa Hernández el 5 de junio de 2018.

67. Espinosa, E., "La Rioja, en el pentagrama de Eliseo." La Rioja, 23 de agosto de 2014, p. 29.

68. La composición inicial sería la siguiente: Presidente, Agapito del Valle López (Presidente a su vez de la Diputación); Vicepresidente, Félix Ros Martínez (Diputado provincial y Presidente de la Comisión de Cultura de la Diputación); Vocales, Antonio Loma-Osario Uriarte (Diputado Visitador de los Establecimientos provinciales de Beneficencia), Pascual Minguillón Tobía (Diputado provincial), Diego Ochagavía Fernández (Vicepresidente del Instituto de Estudios Riojanos), y José María Lope Toledo (Cronista Oficial de La Rioja), "propuesto éste por Patronato por considerarle persona de reconocida competencia en la materia". Secretario, Pedro Eliseo Pinedo López. Actas de la Diputación Provincial de Logroño, 21 de septiembre de 1954, pp. 104v-107.

69. Que será definitivo por muchos años, con ampliaciones de docentes según las necesidades.

70. De ahí que la denominación de la agrupación musical aparezca en determinados momentos como Banda Provincial de Música de Logroño o como Banda de la Academia de Música de Logroño. 
Al aumento progresivo de las matrículas anuales le correspondieron ampliaciones físicas y de recursos humanos $-y$ de derechos laborales de estos, reclamados por Pinedo- que implicaron también un importante incremento en los presupuestos que manejaba el Patronato para la gestión de los estudios.

Pero, una vez puesta en marcha la Academia con las premisas de accesibilidad universal, apertura a todas las clases de la sociedad y a la mayor cantidad de instrumentos posible, más allá de los de la banda, la siguiente idea de Pinedo fue dar validez oficial a estos estudios para que los esfuerzos tuvieran una recompensa, preparando el camino a futuros profesionales de la música. Pinedo explica la necesidad de la declaración de la Academia Provincial de Música de Logroño como Conservatorio ${ }^{71}$, solicitud que se debe de hacer a la Dirección General de Bellas Artes. El proceso de lucha fue largo y constante -aprovechaba, según su viuda, María Teresa Hernández, cualquier oportunidad para explicárselo al político correspondiente- pero dio su fruto cuando en 1965, tras la correspondiente solicitud de la Diputación, se realiza el trámite administrativo y se publica ese mismo año el esperado Decreto $^{72}$ de validez académica para la Academia Provincial de Música de Logroño. Se trataba de que alumnos que realizaban sus estudios en Logroño pudieran validarlos en su sede y no obligarles a examinarse por libre en otras provincias limítrofes, como venía ocurriendo desde el inicio de la institución. Dado que Pinedo había tenido en cuenta todos los requisitos que se indican en el Decreto de 1942 sobre organización de los Conservatorios de Música y Declamación ${ }^{73}$, desde sus inicios en 1954, el proceso administrativo y docente no supuso ningún problema.

\subsection{Actividades musicales (1933-1969)}

Paralelamente a estos proyectos, ampliación de los iniciados en Tudela en pro de la educación musical de calidad y universal y de la dignificación del músico en las bandas, Pinedo no dejó de realizar actividades que supusieran, por un lado, una actividad profesional como músico práctico y, por otro, una complementariedad al sueldo de la Diputación. Esta situación se produjo intermitente pero frecuentemente entre los años treinta y sesenta.

Si bien su principal actividad laboral estaba vinculada a la Banda Provincial de Música de Logroño y a la Academia -ya Conservatorio-, su trabajo en la composición y dirección musical de zarzuelas es digno de valorar. Por

71. Diputación Provincial de Logroño, Actas, 1957, fols. 102v y 103.

72. Decreto 3880/1965, de 23 de diciembre, por el que se reconoce validez académica oficial, con el grado de Conservatorio Elemental, a los estudios de la Academia Provincial de Música, sostenida por la Diputación Provincial de Logroño. BOE número 15, de 18 de enero de 1966, pp. 594 y 595.

73. Decreto de 15 de junio de 1942 sobre organización de los Conservatorios de Música y Declamación. BOE número 185, de 4 de julio de 1942, pp. 4.838-4.840. 
un lado, Pinedo trabajó con la Compañía Lírica de Aficionados (CLA) en el montaje y dirección musical de diversas zarzuelas. Su fundador, Pepe Eizaga escribió el libreto de tres de las zarzuelas que puso en música Pinedo: La Titiritaina (1944), Paloma la desdeñosa (1946) y S. E. [Su Excelencia] El Sainete (s.f.). El trabajo en la dirección le permitió la representación de, por ejemplo en 1961, Katiuska ${ }^{74}$. En el foso, según la prensa local, la Orquesta de Cámara Oria, por él fundada. Muchas de las producciones locales solo se llevaban a escena en unas pocas representaciones, pese a los grandes esfuerzos de su montaje, con poca repercusión y aún menos beneficio. Algunas de ellas se organizaban en colaboración con otras asociaciones locales como la sociedad Círculo La Amistad, con quienes compartían, además de siglas, proyectos. La CLA Pepe Eizaga concedió a Pinedo la "Lira de plata" por su apoyo en favor de la zarzuela ${ }^{75}$.

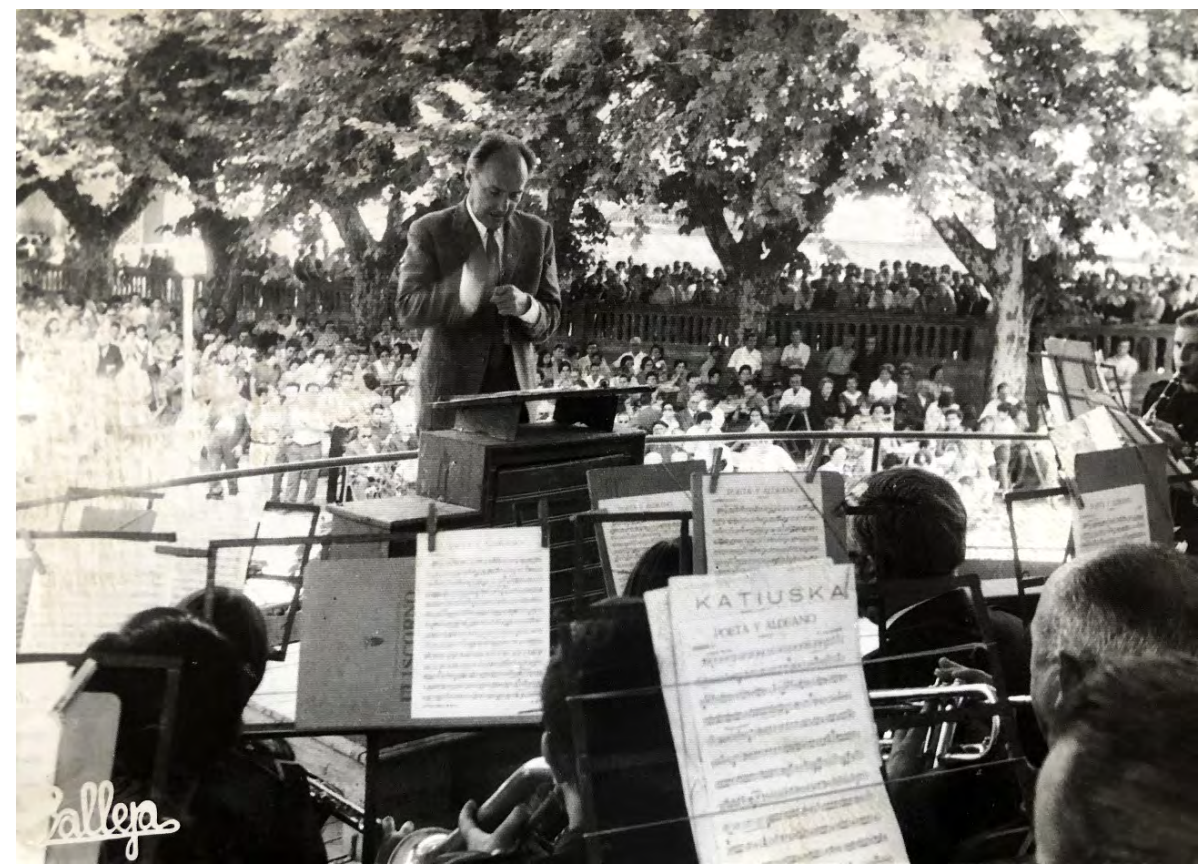

Imagen 3. Pinedo dirigiendo Katiuska a la Banda de Haro, invitado en 1969. Fuente: AMTH.

74. Zarzuela con música de Pablo Sorozábal y libreto de Emilio González del Castillo y Manuel Martí Alonso por la que Pinedo tenía una especial predilección.

75. Hernández Lázaro, J. F., Están escuchando ustedes... los primeros 75 años de EAJ-18. Logroño, Radio Rioja, 2008, p. 47. 
Otro de los trabajos de dirección musical le vinculó con la Sociedad Artística Riojana (SAR). Esta sociedad comprendía a diversos grupos de artistas locales que se unieron con la idea de compartir administración y optimizar recursos, a la vez que apoyarse mutuamente. Pese a que la mayor parte de los miembros eran diletantes, Eliseo Pinedo participa activamente en la SAR desde 1960 -en el proyecto formado por aficionados dentro de su "Cuadro Lírico" - donde aparece en principio como "asesor" junto a José Eizaga y a José M. ${ }^{a}$ Lope Toledo y más adelante como "Maestro Director y Concertador"76. Son numerosas las producciones que llevan a cabo, con más interés que medios. Un hito se produce cuando obtienen, bajo la dirección de Pinedo, el Primer Premio en el V Concurso de Zarzuelas de Torrelavega, Santander, en agosto de $1961^{77}$. El éxito les permitió llevar la producción a diversas localidades del entorno de la provincia de Logroño e intentar nuevos concursos y la participación dentro de los Festivales de España de 1962 en Logroño, con una asistencia masiva de "casi siete mil espectadores" $^{\prime 78}$. Además de su trabajo en la dirección musical de las zarzuelas, se le solicitaban informes de las propuestas y los proyectos musicales para determinar su idoneidad, así como trabajos de supervisión artística a los músicos que preparaban concursos, asesoría técnica y en general colaboraba hasta donde se lo permitían la Banda y la Academia. A partir de 1964 se desvincula de la SAR, pero mantienen relación, uno como responsable del Conservatorio y los otros como asociación colaboradora y organizadora de eventos ${ }^{79}$.

Otra actividad no menos importante es la puesta en marcha en 1960 de un proyecto que Pinedo tenía desde hace años en mente. Se trataba de estudiar determinados repertorios más complejos, desde un punto de vista camerístico. Así surge una formación formada por catorce músicos ${ }^{80}$ cercanos a Pinedo e ilusionados con un proyecto común. Se presentó la Agrupación de Cámara ${ }^{81}$ "Oria" en Logroño el 28 de mayo de 1960². Comenzaron con obras de Granados, Ravel, Rossini, Mozart, Elgar, Finzi y del propio Pinedo, actuando tanto

76. Sociedad Artística Riojana, "Actas de Juntas Directivas y Asambleas." Vol. 1. Logroño, 1952, fol. 12v.

77. Tuvo lugar el 22 de agosto de 1961 en el Coliseum Garcilaso de la ciudad de Torrelavega. El Cuadro Artístico de la SAR interpretó Los gavilanes, zarzuela en tres actos con música de Jacinto Guerrero y libreto de José Ramos Martín.

78. Sociedad Artística Riojana, "Actas...", fol. 15.

79. Por ejemplo, en 1969 la SAR fue requerida por el Conservatorio para participar en los actos en honor a Santa Cecilia, participando con un concierto de piano de Félix Sáenz y otros dos de la Agrupación de Pulso y Púa. Sociedad Artística Riojana, "Actas...", fol. 41.

80. Dentro del grupo se formó también, para el trabajo en paralelo, un quinteto clásico de viento (flauta, oboe, clarinete, trompa y fagot) con un mayor ahínco y dedicación al estudio de obras más complejas. Fuente: entrevista a J. L. Alonso el 3 de octubre de 2018.

81. Aunque en numerosas referencias se define como "orquesta", la denominación usada por Pinedo, y la más adecuada a la realidad, es "agrupación de cámara".

82. Nueva Rioja, 29 de mayo de 1960, p. 2. 
la orquesta a solo como con la colaboración de solistas vocales. Los miembros se reunían casi a diario para trabajar un repertorio que Pinedo ajustaba a las necesidades de la formación ${ }^{83}$. Algunas de esas partituras ${ }^{84}$, con sus anotaciones, se pueden consultar en el Legado Pinedo del Archivo del IER. El proyecto se mantuvo activo durante años con diversos altibajos, colaborando con la SAR e incluso como orquesta de foso del Teatro Bretón, como se ha visto arriba. Además, le sirvió para poner en práctica sus composiciones originales de los últimos años, derivadas del estudio del folclore, con técnicas compositivas personales aplicadas al contrapunto libre y a cierta experimentación contemporánea.

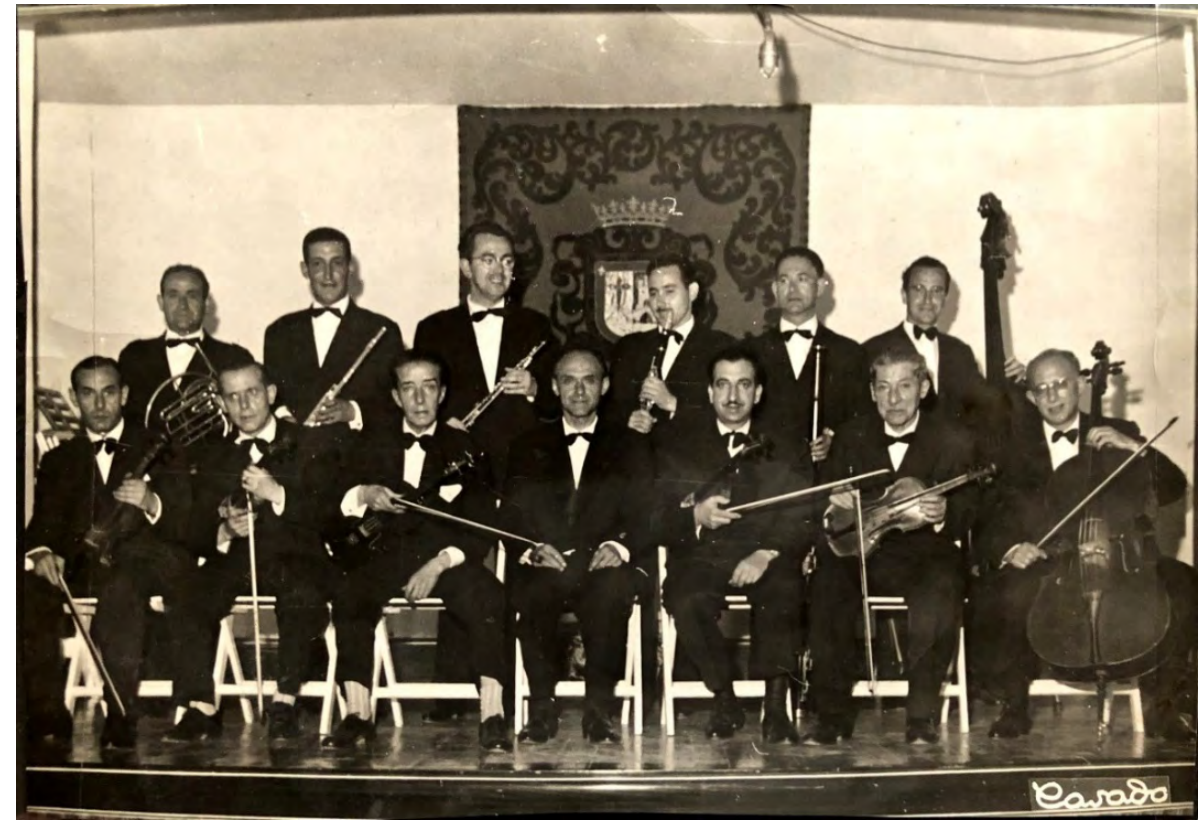

Imagen 4. Agrupación de Cámara Oria, el día de su presentación el 28 de mayo de 1960 en la inauguración de la nueva Sala de Cultura de la Caja Provincial de Ahorros de Logroño. Eliseo Pinedo aparece sentado en el centro. Fuente: AMTH.

83. Programa de mano del concierto de presentación. Fuente: AMTH.

84. Aunque no completas, se pueden consultar las transcripciones de Ocho cantos rusos, Op. 58 de A. Lyadov, el Andante cantabile de P. I. Chaikovski, la Obertura de Las bodas de Fígaro de W. A. Mozart, la Sinfonía incompleta de F. Schubert, La oración del torero de J. Turina, el Intermezzo de Goyescas de E. Granados, o la Obertura de Oberón de C. M. von Weber. Legado Eliseo Pinedo (LEP), Archivo Instituto de Estudios Riojanos. 
Estas composiciones surgen a partir de 1954, tras la ayuda de la Diputación de Logroño a Lope Toledo y Pinedo para "componer una obra netamente popular sobre la [sic] Rioja, fundamentándose este trabajo en la raíz viva de nuestro pueblo" ${ }^{\prime 25}$. A partir de ahí, diversos trabajos le fueron orientando hacia una visión cada vez más personal del folclore ${ }^{86}$, empleándolo como base motívica sobre la que componer, con procedimientos a veces experimentales y en cualquier caso fuera de la tradición tonal. Surgen así obras de envergadura sinfónica y coral como la Suite Oria (1957) y Viejo arcón (1962). Además, en plena ebullición interpretativa y creativa, Eliseo Pinedo y María Teresa Hernández Álvarez contraen matrimonio en 1960 y sus tres hijos nacen en los años siguientes ${ }^{87}$. La vida familiar influye necesariamente en los hábitos de Pinedo, debiendo compaginar el proyecto de conservatorio con el hogar o nuevas composiciones como el Himno provincial (1965).

\subsection{Conservatorio Elemental y Profesional de Música de Logroño (1965)}

Ya se ha explicado que la oficialidad de las enseñanzas musicales no supuso ningún cambio sustancial para el centro docente, puesto que el proceso estuvo preparado con antelación y mucho cuidado, no habiendo "variación en el plan de enseñanzas puesto que siempre se ajustaron a las del Conservatorio de Madrid, del cual dependemos en cuanto [a] la enseñanza se refiere" ${ }^{\prime \prime 8}$. Igualmente, el problema de los alumnos, que debían ir fuera de la provincia a examinarse para obtener la titulación oficial, se mantiene aunque ahora trasladado a otro nivel, ya que los alumnos que continuaban en Logroño más allá del Grado Elemental tenían que volver a examinarse fuera para conseguir su título de Grado Profesional. Además de asumir el notable incremento de las matriculaciones tras la oficialidad de los estudios elementales, el centro debía de adecuar sus estudios a la nueva reglamentación que se vivía a nivel nacional ${ }^{89}$.

Era un momento en el que, según datos estadísticos del Ministerio de Educación y Ciencia, en el curso 1967-1968 el 59\% de los alumnos de conservatorios elementales lo eran en la modalidad de libres, aumentando

85. Diputación Provincial de Logroño, Actas, 1954, fol. 47.

86. Para conocer más sobre la faceta de Pinedo como folclorista, se remite al artículo sobre el tema en Blanco Ruiz, C., "El compositor Eliseo Pinedo: folclorista por descubrir". Belezos. Revista de cultura popular y tradiciones de La Rioja, n. 41 (octubre de 2019), pp. 68-73.

87. Entrevista a M. ${ }^{a}$ Teresa Hernández el 26 de junio de 2018.

88. Memoria del Conservatorio Provincial de Música de Logroño correspondiente al año 1966. ACPMLR.

89. Se establece a nivel nacional una adecuación al denominado popularmente como "Plan del 66" (Decreto 2618/1966 de 10 de septiembre de Reglamentación General de los Conservatorios de Música). 
al $64 \%$ en el caso de los conservatorios profesionales ${ }^{90}$. Por ello, Pinedo actualiza el centro y añade algo de profesorado que permita cumplir la legislación y así volver a solicitar la habilitación, esta vez de nivel profesional. Comienza el trámite administrativo local hasta que, en febrero de 1969, la Diputación de Logroño "acuerda por unanimidad solicitar del Ministerio de Educación y Ciencia que el actual Conservatorio Elemental sea clasificado como Conservatorio de Grado Medio y puedan cursarse en él la plenitud de los estudios necesarios para obtener el título profesional [...] comprometiéndose por su parte, esta Diputación a seguir sosteniendo económicamente al futuro Conservatorio" ${ }^{\prime 1}$.

El trámite en Madrid siguió su curso y apareció publicado el reconocimiento en el Decreto ${ }^{92}$, por el que se eleva al Grado Profesional el Conservatorio Elemental de Música no estatal de Logroño. Desgraciadamente, Eliseo Pinedo no pudo verlo al fallecer en noviembre de 1969, pero su sueño de un Conservatorio Profesional abierto a cualquier ciudadano se hizo realidad.

\section{Conclusiones}

La práctica de la música se ha mostrado tradicionalmente, hasta mediados del siglo XX inclusive, muy vinculada al contexto social y económico. Si se parte de una enseñanza informal -aficionados, bandas, centros de beneficencia, etc.- Ios repertorios implican un amateurismo que relega a la música a una actividad complementaria. Por el contrario, una enseñanza reglada u oficial, con titulación -capital cultural según Bourdieu ${ }^{93}-$, implica una posibilidad laboral y una orientación estética distintas, con un estatus social y cultural diferente. Pasar de uno a otro ámbito, especialmente crecer en el nivel profesional, era una labor tremendamente complicada, puesto que el origen de los estudios determinaba en buena parte el destino laboral.

El caso de Pinedo muestra cómo esto ocurría con frecuencia en la sociedad española de la primera mitad del siglo XX. También sirve para conocer qué estrategias planteó para poder adquirir un capital cultural suficiente que le permitiera escalar en las categorías de su especialidad profesional. El esfuerzo de retrasar los estudios oficiales hasta conseguir el dinero para poder realizarlos y obtener un título superior -mejor dicho: dos, puesto que en

90. Fuente: ACPMLR.

91. Diputación Provincial de Logroño, Actas, 1969, fol. 124v, 125.

92. Decreto 2612/1970, de 24 de julio, por el que se eleva al grado Profesional el Conservatorio Elemental de Música no estatal de Logroño. BOE número 223, de 17 de septiembre de 1970, p. 15.352.

93. Bourdieu, P., Las estrategias de la reproducción social. Buenos Aires, Siglo veintiuno, 2011, pp. 213-219. 
1948 obtiene el de piano en el Conservatorio de Música de Zaragoza ${ }^{94}$ - es una muestra de las dificultades del momento y de las maneras en que se debía actuar. La composición, interpretación y autoedición de música de pequeño repertorio, la dirección y composición de producciones líricas de ámbito local son otros posibles recursos que complementan una profesión que lucha por sobrevivir en la posguerra.

Esta experiencia le sirve a Pinedo, músico polifacético, para llevar a cabo un doble proyecto. Por un lado, lucha porque al músico se le reconozca su valía profesional como a cualquier otro trabajador. Que se le aprecie desde la posición del educando de la banda, del solista en la misma o hasta en la del músico de foso. Se trata de realzar la profesión con la consecución de un sueldo digno y unos derechos y reconocimientos en sociedad. Por otro, con la consecución de un Conservatorio Profesional, cualquier niño de la entonces provincia de Logroño puede comenzar su carrera de música sin depender de su situación económica. Estos estudios permiten la transversalidad de orientación profesional más allá de su origen social, abarcando repertorios diversos, no como compartimentos estancos sino como base sobre la que luego especializarse. Según su viuda, $M^{a}$ Teresa Hernández, el proyecto de Pinedo no es popularizar la música, sino hacerla llegar al pueblo ${ }^{95}$.

\section{Referencias}

Archivos

Archivo del Conservatorio Profesional de Música de La Rioja. Documentación de archivo 1954-1970.

Archivo del Real Conservatorio Superior de Música de Madrid. Expediente académico de Eliseo Pinedo.

Archivo General Militar de Guadalajara. Hoja de Filiación de Eliseo Pinedo en el Ejército Español.

Archivo personal de M. ${ }^{a}$ Teresa Hernández. Logroño.

Ayuntamiento de Haro (1920-1947). Padrones y censo de habitantes. Archivo Municipal de Haro.

Archivo del Ayuntamiento de Logroño. Expediente administrativo de José Cabañero García.

94. Se matricula en el curso 1947-1948 en la modalidad libre y realiza las pruebas de los cinco cursos en un sola día, el 28 de septiembre de 1948, consiguiendo sobresaliente en todos los exámenes. Fuente: boletines de notas del Conservatorio de Zaragoza en el AMTH.

95. Entrevista a M. ${ }^{a}$ Teresa Hernández el 26 de junio 2018. 
Ayuntamiento de Tudela, "Pleno del M. I. Ayuntamiento de Tudela". Actas del Pleno. Tudela, 20 de febrero de 1947.

Ayuntamiento de Tudela, "Pleno del M. I. Ayuntamiento de Tudela". Actas de la Sesión del Pleno. Tudela, 17 de diciembre de 1947, fol. 20v.

Ayuntamiento de Tudela, "Pleno del M. I. Ayuntamiento de Tudela". Actas de la Sesión del Pleno. Tudela, 21 de enero de 1948, fol. 35.

Ayuntamiento de Tudela, "Pleno del M. I. Ayuntamiento de Tudela". Actas de la Sesión del Pleno. Tudela, 8 de abril de 1948, fol. 126.

Ayuntamiento de Tudela, "Pleno del M. I. Ayuntamiento de Tudela". Actas de la Sesión del Pleno. Tudela, 8 de abril de 1948, fol. 128v y 129.

Ayuntamiento de Tudela, "Pleno del M. I. Ayuntamiento de Tudela". Actas de la Sesión del Pleno. Tudela, 12 de enero de 1949, fol. 192.

Ayuntamiento de Zarratón. (1908). Acta de nacimiento, fols. 53r. y 53v. Zarratón: Archivo del Ayuntamiento de Zarratón.

Diputación Provincial de Logroño, Hoja Matriz de servicios de Eliseo Pinedo en la Excma. Diputación Provincial de Logroño". Logroño, 1953.

Diputación Provincial de Logroño, "Actas de la Diputación". Logroño, 8 de abril de 1954, fol. 47.

Diputación Provincial de Logroño, "Actas de la Diputación". Logroño, 28 de diciembre de 1957, fols. 102v y 103.

Diputación Provincial de Logroño, "Actas de la Diputación". Logroño, 26 de febrero de 1969, fols. 124v y 125.

Sociedad Artística Riojana, "Actas de Juntas Directivas y Asambleas". Vol. 1. Logroño, s.e., 1952.

\section{Bibliografía}

Ayala Herrera, I. M., Música y municipio: marco normativo y administración de las bandas civiles en España (1931-1986). Estudio en la provincia de Jaén. Universidad de Granada, s.e., 2013.

Blanco Ruiz, C., "El compositor Eliseo Pinedo: folclorista por descubrir". Belezos. Revista de cultura popular y tradiciones de La Rioja 41 (octubre de 2019), pp. 68-73.

Blanco Ruiz, C., Historia del Festival de Plectro de La Rioja. Una referencia Internacional. Logroño, Instituto de Estudios Riojanos, 2011.

Blanco Ruiz, C., Las claves de la música de M. ${ }^{a}$ Dolores Malumbres. Logroño, Instituto de Estudios Riojanos, 2009.

Bourdieu, P., La distinción. Criterio y bases sociales del gusto. Barcelona, Taurus, 2017 [1979]. 
Bourdieu, P., Las estrategias de la reproducción social. Buenos Aires, Siglo veintiuno, 2011.

Castañón Rodríguez, M. del R., La educación musical en España durante el franquismo (1939-1975). Valladolid, s.e., 2009.

Fernández Soria, J. M., Educación, socialización y legitimación política (España 1931-1970). Valencia, Tirant lo blanch, 1998.

Fuente Rosales, F., Laureada Banda Municipal de Música de Haro. Logroño, Instituto de Estudios Riojanos, 2005.

Gómez, J., La enseñanza de composición en el Conservatorio (páginas históricas). Alicante, Biblioteca Virtual Miguel de Cervantes, 2013.

Gómez Urdáñez, J. L., "De la Caridad a la Filantropía. Antecedentes históricos del Tercer Sector y la Economía Social en La Rioja". Polska.Hiszpania, wczoraj i dzis, Biblioteka Polsko-Iberyjska (Biblioteca Polsko Iberijska) 5 (2012), pp. 181-215.

González Manrique, M. J., "Sociedad, ocio y comunicación de masas en el franquismo (1939-1956)" Dos décadas de cultura artística en el franquismo (1936-1956). Vol. I. Ignacio Luis Henares Cuéllar, José Castillo Ruiz, Gemma Pérez Zalduondo, María Isabel Cabrera García (coords.). Granada, Universidad de Granada, 2001, pp. 143-159.

Guadamuro García, I., "La explotación del teatro lírico en dominio público: el caso de la opereta vienesa en España en las primeras décadas del siglo XX". Musicología en el siglo XXI: nuevos retos, nuevos enfoques, de Adela Presas y Begoña Lolo (coords.). Madrid, Sociedad Española de Musicología, 2018, pp. 569-586.

Hernández Lázaro, J. F., Están escuchando ustedes... los primeros 75 años de EA/-18. Logroño, Radio Rioja, 2008.

Iglesias, A., Escritos de Julio Gómez. Recopilación y comentarios. Madrid, Alpuerto, 1986.

Iglesias, I., "(Re)construyendo la identidad musical española: el jazz y el discurso cultural del franquismo durante la Segunda Guerra Mundial". Historia Actual Online 23 (otoño de 2010), pp. 119-135.

Mansergas Carceller, Y., El Sexteto en la Música Española de Salón: de la Restauración a la Guerra Civil. Valencia, s.e., 2008.

Martínez del Fresno, B., "Realidades y máscaras en la música de la posguerra". Dos décadas de cultura artística en el franquismo (1936-1956). Vol. II. Ignacio Luis Henares Cuéllar, José Castillo Ruiz, Gemma Pérez Zalduondo, María Isabel Cabrera García (coords.). Granada, Universidad de Granada, 2001, pp. 31-82.

Medina, Á., "Música española 1936-1956: rupturas, continuidades y premoniciones". Dos décadas de cultura artística en el franquismo (1936-1956). Vol. I. Ignacio Luis Henares Cuéllar, José Castillo Ruiz, Gemma Pérez Zalduondo, 
María Isabel Cabrera García (coords.). Granada, Universidad de Granada, 2001, pp. 59-74.

Pérez Zalduondo, G., Una música para el "Nuevo Estado". Música, ideología y política en el primer franquismo. Granada, Libargo, 2013.

Pérez Zalduondo, G., "Música y poder en Sevilla (1936-1960)". Música en Sevilla en el Siglo XX. Miguel López Fernández (ed.). Granada. Libargo. 2018, pp. 203-228.

Seguí, S., Manuel Palau (1893-1967). Valencia, Consell Valenciá de Cultura, 1999.

Temes, J. L., El siglo de la Zarzuela. 1850-1950. Madrid: Siruela, 2014.

Toro Egea, O. M., La enseñanza de la música en España (1823-1932): documentación de materiales. Córdoba, Universidad de Córdoba, 2010.

Prensa

Alonso Ruiz, V., "El maestro Pinedo dice cosas interesantes". El Correo EspañolEl Pueblo Vasco, 26 de octubre de 1961, p. 3.

Asociación Nacional de Directores de Bandas de Música Civiles, "¡iGuerra a las Bandas!!". Boletín de la Asociación Nacional de Directores de Bandas de Música Civiles, diciembre 1935, pp. 13-14.

Asociación Nacional de Directores de Bandas de Música Civiles, "A opinar se ha dicho" Boletín de la Asociación Nacional de Directores de Bandas de Música Civiles Año I, n. 9 (octubre de 1935), pp. 5-7.

Decreto de 15 de junio de 1942 sobre organización de los Conservatorios de Música y Declamación. BOE número 185, de 4 de julio de 1942, pp. 4.8384.840 .

Decreto 3880/1965, de 23 de diciembre, por el que se reconoce validez académica oficial, con el grado de Conservatorio Elemental, a los estudios de la Academia Provincial de Música, sostenida por la Diputación Provincial de Logroño. BOE número 15, de 18 de enero de 1966, pp. 594 y 595.

Decreto 2618/1966, de 10 de septiembre, sobre Reglamentación general de los Conservatorios de Música. BOE número 254, de 24 de octubre de 1966, pp. 13.381-13.387.

Decreto 2612/1970, de 24 de julio, por el que se eleva al grado Profesional el Conservatorio Elemental de Música no estatal de Logroño. BOE número 223, de 17 de septiembre de 1970, p. 15.352.

Espinosa, E., "La Rioja, en el pentagrama de Eliseo". La Rioja, 23 de agosto de 2014, p. 29.

Nueva Rioja, "Brillantes funciones de homenaje a María del Pilar Santos". Nueva Rioja, 30 de marzo de 1963, p. 10. 
Nueva Rioja, "Excelente presentación de 'Oria', Agrupación Musical de Cámara y gran actuación de cuatro artistas locales". Nueva Rioja, 29 de mayo de 1960, p. 2.

Nueva Rioja, "Hoy presenta la S.A.R. en el Espolón 'Los Gavilanes'". Nueva Rioja, 13 de septiembre de 1962, p. 3.

Nueva Rioja, "Un gran concierto de la Sociedad Artística Riojana en honor de Santa Cecilia". Nueva Rioja, 3 de diciembre de 1962, p. 10.

Orden de 9 de julio de 1940 por la que se convocan oposiciones para ingreso en el Cuerpo de Directores de Bandas de Música. BOE núm. 194, de 12 de julio de 1940, del Ministerio de la Gobernación, p. 4.824.

\section{Entrevistas}

Alonso, J. L. (3 y 30 octubre de 2018). Entrevistas a José Luis Alonso. (C. Blanco Ruiz, entrevistador).

Hernández, M. T. (5, 13, 19, 26 de junio, 17, 26, 31 de julio, 11 de septiembre de 2018 y 17 de abril de 2019). Entrevistas a M. ${ }^{a}$ Teresa Hernández. (C. Blanco Ruiz, entrevistador). 